\title{
HOMICÍDIOS DE MULHERES E MENINAS NO ESTADO DO PARANÁ: UMA ANÁLISE TERRITORIAL RETROSPECTIVA DE 2014 A 2018
}

\section{Clóvis Wanzinack}

Universidade Federal do Paraná - Setor Litoral Professor Adjunto, Câmara de Administração Pública

Matinhos, Paraná - Brasil

clovis_cwb@yahoo.com.br

\section{Mirian Gomes de Souza}

Universidade Federal do Paraná - Setor Litoral Discente do PPGDTS

Paranaguá, Paraná - Brasil

gmmirian@gmail.com

\section{Vanessa de Oliveira Lucchesi}

Universidade Federal do Paraná - Setor Litoral Discente do PPGDTS

Paranaguá, Paraná - Brasil

lucchesi.fono@gmail.com

\section{Marcos Claudio Signorelli}

Universidade Federal do Paraná - Setor Litoral Professor Associado, Câmara de Saúde Coletiva

Matinhos, Paraná - Brasil

signorelli.marcos@gmail.com

Recebido em 09/10/2020. Aprovado em 09/1 1/2020.

DOI: dx.doi.org/10.5380/guaju.v6i2.77269

\section{Resumo}

O Brasil é o país com maior número absoluto de homicídios no mundo. Objetivamos realizar uma análise temporal e territorial dos homicídios contra mulheres e meninas no estado do Paraná entre 2014 e 2018. A metodologia utilizada foi um estudo ecológico retrospectivo de tendência temporal dos homicídios no período. Os dados oficiais de homicídios foram obtidos no Sistema de Informações sobre Mortalidade (SIM), do Ministério da Saúde, enquanto dados da população feminina foram obtidos do Instituto Brasileiro de Geografia e Estatística (IBGE). Os dados foram tabulados e analisados por meio de estatística descritiva, incluindo cálculo de taxas por 100 mil mulheres, características das vítimas, causa do homicídio e distribuição geográfica, os quais foram plotados em mapas no software QGIS. Os principais achados foram: 1 ) redução de $27 \%$ no número de homicídios contra mulheres e meninas no Paraná entre 2014 e 2018; 2) as principais causas foram por armas de fogo (44\%), seguidas de objetos cortantes/perfurantes (32\%); 3) o perfil das vítimas era predominantemente de mulheres jovens, de 25 a 34 anos (27\%), seguido por 15 a 24 anos (25\%); brancas (77\%), com 4 a 7 anos de escolaridade $(36 \%)$ e solteiras $(61 \%)$; 4$)$ o local mais comum do homicídio foi o domicílio, 
contabilizando 35\% dos casos; 5) geograficamente, a região metropolitana de Curitiba, litoral, região de fronteira com o Paraguai e com o Mato Grosso do Sul, assim como o entorno de cidades como Londrina, Cascavel, Maringá e Paranavaí foram alguns clusters que apresentaram taxas de homicídio acima da média do estado.

Palavras-chave: Homicídio. Violência de gênero. Mulher. Agressões. Paraná.

\title{
Homicides of women and girls in the state of Paraná, Brazil: a territorial retrospective analysis from 2014 to 2018
}

\begin{abstract}
Brazil is the country with the highest number of homicides in the world. We aimed to conduct a temporal and territorial analysis of homicides against women and girls in the State of Paraná, Brazil, between 2014 and 2018. We adopted a retrospective ecological methodology based on temporal trends of homicides in the period. We collected official homicide data from the Ministry of Health's Mortality Information System (SIM); and female population data were collected from the Brazilian Institute of Geography and Statistics (IBGE). The data were tabulated and we analyzed using descriptive statistics, including calculation of rates per 100 thousand women, characteristics of the victims, cause of homicide and geographic distribution, which were plotted on maps in the QGIS software. The main findings were: 1) a 27\% reduction in the number of homicides against women and girls in Paraná between 2014 and 2018; 2) the main causes were firearms (44\%), followed by sharp objects (32\%); 3) the profile of the victims was predominantly young women, from 25 to 34 years old (27\%), followed by 15 to 24 years old (25\%), white (77\%), with 4 to 7 years of education (36\%) and single (61\%); 4) the most common place of homicide was the home, accounting for 35\% of cases; 5) geographically, the metropolitan region of Curitiba, the coast, the border with Paraguay and Mato Grosso do Sul's State, as well as the surroundings of cities like Londrina, Cascavel, Maringá and Paranavaí were some clusters which homicide rates were above the state average.
\end{abstract}

Keywords: Homicide. Gender-based violence. Women. Aggression. Paraná. 


\section{Introdução}

O Brasil registra, em números absolutos, a maior quantidade de homicídios do planeta, correspondendo a cerca de $10 \%$ de todos os homicídios do mundo (WORLD HEALTH ORGANIZATION, 2014). Já em relação aos homicídios especificamente contra mulheres, em termos relativos (proporcionais ao tamanho da população), apresenta a $5^{\text {a }}$ maior taxa do ranking mundial, atrás apenas de El Salvador, Colômbia, Guatemala e Rússia (WAISELFISZ, 2015). Isso significa que as mulheres brasileiras correm mais risco de perder a vida violentamente do que em países em situação de guerra e conflitos, como a Síria e o Iraque, por exemplo. Entretanto, o homicídio é apenas a ponta do iceberg relacionada às diferentes formas de violência e opressão contra mulheres e meninas (OMS, 2020). No ano de 2018, houve 4.519 assassinatos de mulheres no Brasil, segundo o Atlas da Violência produzido pelo Ipea (Instituto de Pesquisa Econômica Aplicada) e pelo Fórum Brasileiro de Segurança Pública, com uma taxa de 4,3 mortes por 100 mil mulheres, das quais $68 \%$ eram negras (CERQUEIRA; BUENO; ALVES; LIMA et al., 2020).

Segundo dados publicados (LIMA; BUENO, 2019) no $13^{\circ}$ Anuário Brasileiro de Segurança Pública, mais de 66.041 casos de violência sexual e 1.206 casos de feminicídio foram registrados no Brasil no ano de 2018. Os dados ainda mostram que $88,8 \%$ dos agressores são os companheiros das vítimas ou ex-companheiros. Para combater essa realidade, políticas públicas de proteção às mulheres são de suma importância. No Brasil, desde a década de 1980 houve a implantação de Delegacias Especializadas de Atendimento à Mulher (Deam), que se constituíram em importantes espaços de empoderamento (empowerment) das mulheres em situação de violência. Outra importante Política Pública nesse sentido foi a implantação da Lei 11.340, de 07 de agosto de 2006, conhecida como "Lei Maria da Penha", sancionada pelo presidente Luiz Inácio Lula da Silva, a qual:

\footnotetext{
Cria mecanismos para coibir a violência doméstica e familiar contra a mulher, nos termos do § 80 do art. 226 da Constituição Federal, da Convenção sobre a Eliminação de Todas as Formas de Discriminação contra as Mulheres e da Convenção Interamericana para Prevenir, Punir e Erradicar a Violência contra a Mulher; dispõe sobre a criação dos Juizados de Violência Doméstica e Familiar contra a Mulher; altera o Código de Processo Penal, o Código Penal e a Lei de Execução Penal; e dá outras providências. (BRASIL, 2006).
} 
Após a aprovação dessa lei, observa-se que ainda existem desafios relativos ao quantitativo de casos de violência contra as mulheres. Em outro importante estudo realizado recentemente, foram contabilizados 4,8 assassinatos a cada 100 mil mulheres, número que coloca o Brasil no $5^{\circ}$ lugar do ranking de países nesse tipo de crime. Dos 4.762 assassinatos de mulheres registrados em 2013, 50,3\% foram cometidos por familiares, sendo que em 33,2\% desses casos, o crime foi praticado pelo parceiro ou ex-parceiro. Esses números representam 13 homicídios femininos diários no ano de 2013 (WAISELFISZ, 2015).

As mudanças nesse cenário têm sido discretas, observando-se muito mais uma queda no crescimento do que uma diminuição de casos de violência propriamente dita. No período de 2006 a 2013, com a vigência da Lei Maria da Penha, o crescimento do número desses homicídios caiu para $2,6 \%$ ao ano e o crescimento das taxas caiu para $1,7 \%$ ao ano. Levando em consideração o crescimento da população feminina, que nesse período passou de 89,8 para 99,8 milhões (crescimento de 11,1\%), vemos que a taxa nacional de homicídio, que em 2003 era de 4,4 por 100 mil mulheres, passa para 4,8 em 2013, crescimento de 8,8\% na década. Limitando a análise ao período de vigência da Lei Maria da Penha, que entrou em vigor em 2006, observamos que a maior parte desse aumento decenal aconteceu sob a égide da nova lei: 18,4\% nos números e 12,5\% nas taxas entre 2006 e 2013. Se em um primeiro momento, em 2007, registrou-se uma queda expressiva nas taxas, de 4,2 para 3,9 por 100 mil mulheres, rapidamente a violência homicida recuperou sua escalada, ultrapassando a taxa de 2006. Mas apesar das taxas continuarem aumentando, observamos que a partir de 2010 arrefece o ímpeto desse crescimento (WAISELFISZ, 2015).

Segundo estudo de Garcia, Freitas, Silva e Hofmann (2015), foi registrada uma taxa de 5,86 feminicídios no Brasil no triênio de 2009 a 2011 por 100.000 mulheres. Todos enquadrados em óbitos de mulheres por agressão, nos quais foram usados principalmente armas de fogo ( $50 \%$ dos casos) e instrumentos perfurocortantes ( $1 / 3$ dos casos). Concluíram que as principais vítimas foram mulheres jovens, negras e com baixa escolaridade, residentes nas regiões Nordeste, Centro-Oeste e Norte.

Em estudo realizado no município de Goiânia (GO), identificou-se o perfil de mortes violentas de mulheres a partir da base de dados do Sistema de Informação de Mortalidade (SIM). A população investigada era formada predominantemente por mulheres jovens, pardas, solteiras, com baixo nível de escolaridade e moradoras de regiões periféricas do município, sendo que 376 mulheres morreram por agressão entre 2008 e 2015 (DAVID; MINAMISAVA; VITORINO; ROCHA et al., 2020) 
Cardoso e Faúndes (2006) investigaram óbitos de mulheres em idade fértil na cidade de Cascavel (PR) entre os anos de 1991 e 2000. Registraram que mais da metade das mortes por causas externas foram ocasionadas por acidentes de trânsito e quase um terço por homicídios e suicídios em proporções quase iguais. A mortalidade por homicídios, em sua maioria, foi provocada por arma de fogo (19 óbitos, contra 15 por arma branca e 3 por objeto contundente). Já os suicídios foram efetivados: por enforcamento, sufocação ou estrangulamento (11 óbitos) e por disparo de arma de fogo (10 óbitos). Relacionando os óbitos desse mesmo grupo em outras regiões do país, os autores observaram que o município de Cascavel obteve o maior coeficiente nas causas externas, seguido pelas doenças cardiovasculares e pelas neoplasias, e mais de longe pelas causas infecto-parasitárias e mortes maternas; em nenhuma das outras cidades estudadas as causas externas ocuparam o primeiro lugar.

Com o objetivo de realizar uma análise da evolução temporal e conhecer o perfil de mortalidade no estado do Paraná entre os anos de 1980 e 2006, Kleinschmitt, Wadi e Staduto (2010) analisaram dados do Sistema de Informação sobre Mortalidade (SIM) do Ministério da Saúde (MS). Verificaram que homens foram a maioria das vítimas de homicídio nesse período. No total, das 44.720 mortes por homicídio no estado do Paraná, 40.182 eram de homens. As taxas de mortalidade do sexo feminino, em oposição, não chegaram a atingir três mortes por 100 mil habitantes durante o período de 1980 a 2006. Do total de 44.720 mortes por homicídio do estado, em 4.473 deles as vítimas eram mulheres.

Já o estudo que analisou dados de homicídio na região de fronteira desse mesmo estado, em relação à mortalidade feminina na linha de fronteira, sinaliza que houve aumento de $3,7 \%$ das taxas, ao passo que no estado houve aumento de $42,5 \%$ no número total de mulheres. Em relação à proporção média masculino/feminino constatada, esta foi de 13:1 para a linha de fronteira e de 11:1 para a região não fronteiriça do Paraná. Segundo os autores, a mortalidade feminina na linha da fronteira teve a mesma proporção. Tal comportamento pode estar atrelado à violência contra a mulher nas relações de gênero e, também, a fatores culturais envolvendo Brasil, Paraguai e Argentina. Nessas realidades ocorrem a dominação masculina, que pode estar ligada à falta de proteção contra as diferentes formas de violência domésticas e crimes passionais (NOGUEIRA; XAVIER-GOMES; BARBOSA, 2020).

Neste estudo consideramos o termo "homicídio contra mulheres e meninas" em invés de "feminicídios", pois embora uma boa parte desses homicídios seja motivada por questões de gênero e pela condição específica da mulher, nem todos os homicídios que 
constam nas bases de dados consultadas se enquadram nessa categoria. A Lei n 13.104 , de 2015, conhecida como Lei do Feminicídio, alterou o Código Penal e enquadrou esse crime como hediondo, trazendo em seu texto que:

\footnotetext{
VI - Homicídio contra a mulher por razões da condição do sexo feminino [...] $\S 2^{\circ}$-A Considera-se que há razões de condição de sexo feminino quando o crime envolve:

I - Violência doméstica e familiar;

II - Menosprezo ou discriminação à condição de mulher. [...] (BRASIL, 2015).
}

Após a criação da Lei do Feminicídio, Daltoé e Bazzo (2018) investigaram estatisticamente os casos no estado do Paraná (PR) no primeiro ano de vigência da lei. Analisaram dados das denúncias criminais registradas pelo Ministério Público do PR entre março de 2015 e março de 2016. Relataram o registro de 156 feminicídios que ocorreram em 89 diferentes municípios do estado do Paraná. Do total, 97 (62,1\%) casos foram crimes tentados e em $57(36,5 \%)$ houve a consumação do crime de homicídio, gerando como resultado a morte da mulher.

Diante desses pressupostos que incluem a recente aprovação da Lei do Feminicídio e considerando as lacunas existentes acerca de estudos recentes sobre os homicídios de mulheres e meninas com recorte territorial específico no estado do Paraná, propomos esta pesquisa. Este estudo tem como objetivo realizar uma análise retrospectiva temporal dos homicídios registrados contra mulheres e meninas no estado do Paraná entre os anos de 2014 a 2018, buscando definir o perfil das vítimas, os meios de agressão, os locais de ocorrência e a distribuição territorial dos homicídios.

\section{Metodologia}

Estudo ecológico retrospectivo de tendência temporal dos homicídios registrados contra mulheres e meninas no estado do Paraná entre os anos de 2014 a 2018. Os dados oficiais de mortalidade por homicídio foram obtidos no Sistema de Informações sobre Mortalidade (SIM), do Ministério da Saúde, sendo 2018 o último ano com dados disponíveis consolidados, objetivando, portanto, um retrato atualizado do problema. O banco de dados do SIM é de acesso público e contém registros relativos a todos os óbitos (de todas as causas 
de morte) da população. Os tipos de óbitos seguem a lista de tabulação da Classificação Internacional de Doenças - 10 $0^{a}$ Revisão (CID-BR-10), elaborada pela Secretaria de Vigilância em Saúde do Ministério da Saúde. Para extração apenas dos registros de homicídios, utilizamos a seleção de acordo com as categorias de causa (códigos CID-BR-10) classificadas como: agressões interpessoais, adquiridas pelos códigos X85-Y09, e também por intervenção legal e operações de guerra, pelos códigos Y35-Y36 (sendo essas últimas as mortes causadas por policiais/agentes da lei). O SIM revela os dados das vítimas de forma anônima, incluindo sexo, faixa etária, raça/cor, escolaridade, estado civil, e ainda o local da ocorrência, o método utilizado para a agressão letal e o município onde o homicídio foi consumado.

Para o cálculo das taxas, foram coletados dados referentes à população feminina do Instituto Brasileiro de Geografia e Estatística (IBGE) do ano de 2010, que foi o ano do último censo populacional. A partir do cruzamento entre os dados populacionais (IBGE) e de homicídios (2014 a 2018 - SIM), foram calculadas as taxas de homicídios proporcionais, expressas na razão de número de homicídios por 100.000 mulheres, para cada um dos 399 municípios paranaenses. Também foram tabulados os dados a respeito das causas dos homicídios femininos, assim como características das vítimas (faixa etária, raça/cor, escolaridade, estado civil e também local de ocorrência). $O$ agrupamento e análise dos dados foi realizado pelo software Microsoft Excel 2009. A análise espacial foi feita através do software Quantum Geographic Information System (QGIS) 3.12.1, um sistema de informação geográfica livre e aberto, o qual permitiu a visualização, edição e análise de dados georreferenciados com as respectivas taxas de homicídios por região, possibilitando uma análise territorial do problema. Desse modo, foi possível analisar quais municípios e regiões registraram as maiores taxas médias de homicídios contra pessoas do sexo feminino, configurando-se, por conseguinte, em regiões mais violentas para mulheres e meninas.

\section{Resultados e Discussão}

Os achados deste estudo revelam que o número absoluto de homicídios contra mulheres e meninas registrados no estado do Paraná foi de 284 homicídios em 2014, 242 em 2015, 239 em 2016, 242 em 2017 e 208 em 2018, totalizando 1.215 homicídios femininos no período 2014-2018. Esse número representa uma taxa média estadual de 4,57 homicídios por 100 mil mulheres no período. Observa-se que entre 2014 e 2018 houve uma redução 
de aproximadamente $27 \%$ na quantidade de homicídios registrados contra mulheres e meninas no estado do Paraná. Tal resultado poderia ser decorrente da aprovação da Lei do Feminicídio, sancionada em 2015, portanto, no período compreendido na análise deste estudo.

Há uma tendência no senso comum de denominar todo homicídio de pessoa do sexo feminino como feminicídio (ou femicídio). Entretanto, nem todo homicídio de pessoa do sexo feminino pode ser enquadrado como feminicídio. Cabe destacar que os feminicídios são somente os homicídios motivados pela condição de gênero da mulher e fruto de um continuum de terror antifeminino, ou seja, homicídios cometidos pelo fato de a vítima ser uma mulher, pela condição de inferioridade que as mulheres tradicionalmente ocupam na sociedade e, na maioria das vezes, motivados por relacionamentos abusivos por parte de um parceiro íntimo (GOMES, 2018; MENEGHEL; HIRAKATA, 2011). Apesar de proporcionalmente os homens serem a maioria das vítimas de homicídio (TAVARES; CATALAN; ROMANO; MELO, 2016), não se pode desconsiderar a assimetria negativa que as mulheres ocupam na sociedade. Trata-se de uma desigualdade de poder, causada pela assimetria de gênero entre homens e mulheres, que tem como consequência fatal o homicídio baseado nessas relações desiguais de gênero e poder (GARCIA; FREITAS; SILVA; HÖFELMANN, 2015; LEITES; MENEGHEL; HIRAKATA, 2014).

Com base em nossa análise, do total de 1.215 homicídios de mulheres e meninas registrados no Paraná entre 2014 e 2018, a principal causa foi decorrente do uso de armas de fogo, conforme pode ser observado na Tabela 1, respondendo por aproximadamente $44 \%$ dos óbitos. O Atlas da Violência de 2020 cita a importância do controle de uso de armas no Brasil, já que $71,1 \%$ dos assassinatos no nosso país foram cometidos por arma de fogo. Entretanto, após o Estatuto do Desarmamento, o índice dos assassinatos caiu de 5,9 para $0,9 \%$ ao ano. A segunda causa mais prevalente foi por objetos cortantes ou perfurantes, como facas e similares (32\%); a terceira causa foi por meios de enforcamento, estrangulamento e sufocamento (9\%) (CERQUEIRA; BUENO; ALVES; LIMA et al., 2020). 
Tabela 01 - Números absolutos e porcentagem de homicídios contra mulheres e meninas no Paraná, segundo categoria de classificação internacional de doenças - CID10, no período entre 2014 a 2018

\begin{tabular}{|c|c|c|}
\hline Óbitos por ocorrência segundo categoria CID-10 & $\begin{array}{l}\text { Óbitos por } \\
\text { ocorrência }\end{array}$ & $\%$ \\
\hline X85 Agressão por meio de drogas, medicamentos e substâncias biológicas & 1 & 0,08 \\
\hline X91 Agressão por meio de enforcamento, estrangulamento e sufocação & 104 & 8,56 \\
\hline X92 Agressão por meio de afogamento e submersão & 5 & 0,41 \\
\hline X93 Agressão disparo de arma de fogo de mão & 68 & 5,6 \\
\hline X94 Agressão disparo arma fogo de maior calibre & 10 & 0,82 \\
\hline $\begin{array}{l}\text { X95 Agressão por meio de disparo de outra arma de fogo ou de arma não } \\
\text { especificada }\end{array}$ & 457 & 37,61 \\
\hline X97 Agressão por meio de fumaça fogo e chamas & 21 & 1,73 \\
\hline X98 Agressão vapor água gases ou objetos quentes & 1 & 0,08 \\
\hline X99 Agressão objeto cortante ou penetrante & 385 & 31,69 \\
\hline Y00 Agressão por meio de um objeto contundente & 70 & 5,76 \\
\hline $\begin{array}{l}\text { Y02 Agressão por meio de projeção ou colocação da vítima diante de um objeto } \\
\text { em movimento }\end{array}$ & 1 & 0,08 \\
\hline Y03 Agressão por meio de impacto veia a motor & 4 & 0,33 \\
\hline Y04 Agressão por meio de força corporal & 51 & 4,2 \\
\hline Y05 Agressão sexual por meio de força física & 3 & 0,25 \\
\hline Y06 Negligência e abandono & 1 & 0,08 \\
\hline Y07 Outras síndromes de maus-tratos & 1 & 0,08 \\
\hline Y08 Agressão por outros meios especificados & 7 & 0,58 \\
\hline Y09 Agressão por meios não especificados & 24 & 1,98 \\
\hline Y35 Intervenção legal & 1 & 0,08 \\
\hline TOTAL & 1215 & 100 \\
\hline
\end{tabular}

Fonte: SIM, compilado pelos autores (2020).

A Tabela 2 evidencia a faixa etária das vítimas do sexo feminino que sofreram homicídios no estado do Paraná durante o período estudado. Como incluímos em nossa análise homicídios femininos registrados em todas as faixas etárias, optamos pela adoção do termo "homicídio de mulheres e meninas", uma vez que a OMS considera como meninas as que possuem até 15 anos, não sendo, portanto, consideradas mulheres. A perspectiva feminista também chama atenção para esses dois grupos vulneráveis, realçando as especificidades que cada um desses grupos etários possui, requerendo políticas públicas específicas para cada um. As faixas etárias com maior número de vítimas são dos 25 aos 34 anos (27\% das vítimas) e dos 15 aos 24 anos (25\%), demonstrando que as mulheres mais jovens (adultas jovens e adolescentes) são as que se encontram mais vulneráveis a sofrer homicídio. Esses achados são confirmados por outros estudos realizados no Brasil. Souza, 
Meira, Ribeiro, Santos et al. (2017) citam em sua pesquisa homicídios de mulheres nas distintas regiões brasileiras nos últimos 35 anos, relatando que em todas as regiões geográficas do Brasil as mulheres jovens correm maior risco de homicídio. Esses homicídios originam dano socioeconômico, em decorrência da perda de anos potenciais de vida de mulheres jovens, além de ônus jurídicos, carcerários, bem como para a saúde pública, com intenso sofrimento físico e psicológico para os familiares das vítimas (SOUZA; MEIRA; RIBEIRO; SANTOS et al., 2017)

As faixas etárias mais avançadas, de idosas (acima de 65 anos), apresentam baixo número de homicídios (menos de 6\% do total), em comparação com as jovens eadultas jovens. O mesmo vale para as faixas etárias menores, de meninas de até 14 anos, que representam menos de 4\% das vítimas do sexo feminino. Portanto, sem minimizar as mortes de idosas e meninas, a prevalência dos dados revela que o grande foco no direcionamento de ações e políticas públicas deve se concentrar nas faixas etárias médias, que compreendem mulheres jovens, adultas jovens e mulheres adultas, englobando a fase denominada "reprodutiva" das mulheres.

Tabela 02 - Números absolutos e porcentagem de homicídios contra mulheres e meninas no Paraná, segundo faixa etária, raça/cor e escolaridade, no período entre 2014 a 2018

\begin{tabular}{|l|c|c|}
\hline \multicolumn{1}{|c|}{ Faixa etária (Opas*) } & Óbitos por ocorrência & $\%$ \\
\hline Menor de 1 ano & 9 & 0,74 \\
\hline 1 a 4 anos & 8 & 0,66 \\
\hline 5 a 14 anos & 35 & 2,88 \\
\hline 15 a 24 anos & 304 & 25,02 \\
\hline 25 a 34 anos & 323 & 26,58 \\
\hline 35 a 44 anos & 239 & 19,67 \\
\hline 45 a 54 anos & 150 & 12,35 \\
\hline 55 a 64 anos & 77 & 6,34 \\
\hline 65 a 74 anos & 40 & 3,29 \\
\hline 75 anos e mais & 24 & 1,98 \\
\hline Idade ignorada & 6 & 0,49 \\
\hline & 6 & $\%$ \\
\hline Branca & 939 & 77,28 \\
\hline Preta & 42 & 3,46 \\
\hline Amarela & 3 & 0,25 \\
\hline Parda & 208 & 17,12 \\
\hline Indígena & 6 & 0,49 \\
\hline Ignorado & 17 & 1,4 \\
\hline
\end{tabular}




\begin{tabular}{|l|c|c|}
\hline \multicolumn{1}{|c|}{ Escolaridade } & Óbitos por ocorrência & $\%$ \\
\hline Nenhuma & 44 & 3,62 \\
\hline 1 a 3 anos & 154 & 12,67 \\
\hline 4 a 7 anos & 440 & 36,21 \\
\hline 8 a 11 anos & 420 & 34,57 \\
\hline 12 anos e mais & 88 & 7,24 \\
\hline Ignorado & 69 & 5,68 \\
\hline TOTAL & $\mathbf{1 2 1 5}$ & $\mathbf{1 0 0}$ \\
\hline
\end{tabular}

Fonte: SIM, compilado pelos autores (2020).

Nota: A faixa etária segue categorização da Organização Pan-Americana da Saúde (Opas).

Já em relação às características das vítimas, conforme se observa na Tabela 2, a maioria das vítimas é da raça/cor branca (77\%), seguida pela parda (17\%) e preta (3\%). Essas proporções seguem, portanto, o padrão da composição racial da população do estado segundo o Censo 2010 no que se refere ao Paraná, cuja composição de mulheres era de $71,34 \%$ brancas, $24,34 \%$ pardas e $2,88 \%$ pretas. Portanto, diferentemente de outros estudos de abrangência nacional (CERQUEIRA; BUENO; ALVES; LIMA et al., 2020), no Paraná as mulheres negras não se constituem na maior parte das vítimas de homicídio.

Com relação à escolaridade, 36\% das vítimas tinham de 4 a 7 anos de estudos, $35 \%$ de 8 a 11 anos de estudos e 13\% de 1 a 3 anos de estudos, o que corresponde ao nível de Educação Básica. Somente 7\% das vítimas tinham 12 anos de estudos ou mais, o que corresponde à Educação Superior, sugerindo que a escolaridade pode ser um fator de proteção contra os homicídios, uma vez que a maioria das vítimas possuía baixa escolaridade.

Com relação ao estado civil (Tabela 3), observa-se que a grande maioria (61\%) era solteira, realçando o fato de que as mais vulneráveis não estavam albergadas na categoria de casadas, que responderam por $15 \%$ do total de vítimas de homicídio, seguidas das separadas judicialmente, que computaram $7 \%$. 
Tabela 03 - Números absolutos e porcentagem de homicídios contra mulheres e meninas noParaná, segundo estado civil e local de ocorrência, no período entre 2014 a 2018

\begin{tabular}{|l|c|c|}
\hline \multicolumn{1}{|c|}{ Estado civil } & Óbitos por ocorrência & $\%$ \\
\hline Solteira & 742 & 61,07 \\
\hline Casada & 186 & 15,31 \\
\hline Viúva & 55 & 4,53 \\
\hline Separada judicialmente & 88 & 7,24 \\
\hline Outro & 72 & 5,93 \\
\hline Ignorado & 72 & 5,93 \\
\hline \multicolumn{1}{|c|}{ Local ocorrência } & Óbitos por ocorrência & $\%$ \\
\hline Hospital & 235 & 19,34 \\
\hline Outro estabelecimento de saúde & 23 & 1,89 \\
\hline Domicílio & 427 & 35,14 \\
\hline Via pública & 292 & 24,03 \\
\hline Outro & 235 & 19,34 \\
\hline Ignorado & 3 & 0,25 \\
\hline TOTAL & $\mathbf{1 2 1 5}$ & $\mathbf{1 0 0}$ \\
\hline
\end{tabular}

Fonte: SIM, compilado pelos autores (2020).

Já com relação ao local de ocorrência (Tabela 3), um dado que chama bastante atenção é que a maior parte dos homicídios femininos ocorreu dentro de casa (35\%). Logo, as mulheres correm mais risco de serem assassinadas dentro da própria casa, e não nas ruas (24\%), como se poderia imaginar. Portanto, nosso estudo reforça outros estudos (LEITES; MENEGHEL; HIRAKATA, 2014), de que o espaço onde as mulheres correm mais perigo de sofrerem violência é dentro de casa. Os hospitais (19\%) também aparecem com alta proporção, uma vez que muitas vítimas são levadas a centros hospitalares ainda com vida, porém, não resistem às complicações e os óbitos acabam acontecendo nos hospitais, sendo, portanto, registrado esse lugar como local da morte.

A Organização Mundial da Saúde (OMS) manifesta a urgência de aperfeiçoar a capacidade dos serviços de saúde de reconhecerem a violência doméstica contra a mulher e o risco de feminicídio. O direcionamento apropriado da mulher agredida e seu acesso aos serviços de segurança pública e justiça para a obtenção de medidas protetivas podem fazer a diferença entre a vida e a morte (GARCIA; FREITAS; SILVA; HÖFELMANN, 2015).

As desigualdades sociais, bem como níveis de institucionalidade, são variáveis determinantes na maior prevalência de homicídios. Pessoas com menor escolaridade se 
apresentaram como o maior grupo de vítimas de homicídios, independentemente da raça/ cor, quando comparadas com vítimas de maior escolaridade. A escolaridade pode reduzir significativamente o risco de homicídio, portanto, acredita-se ser esse um importante fator protetivo. Todavia, também é um item que não pode ser analisado isoladamente dos outros Determinantes Sociais da Saúde, uma vez que menor escolaridade pode estar ligada a um menor nível socioeconômico, o que poderia consequentemente estar ligado a uma maior exposição à violência e homicídios (ARAÚJO; COSTA; HOGAN; MOTA et al., 2009; REICHENHEIM; DE SOUZA; MORAES; DE MELLO JORGE et al., 2011).

Figura 01 - taxas médias de homicídios por 100 mil mulheres no paraná, no período entre 2014 e $2018^{*}$

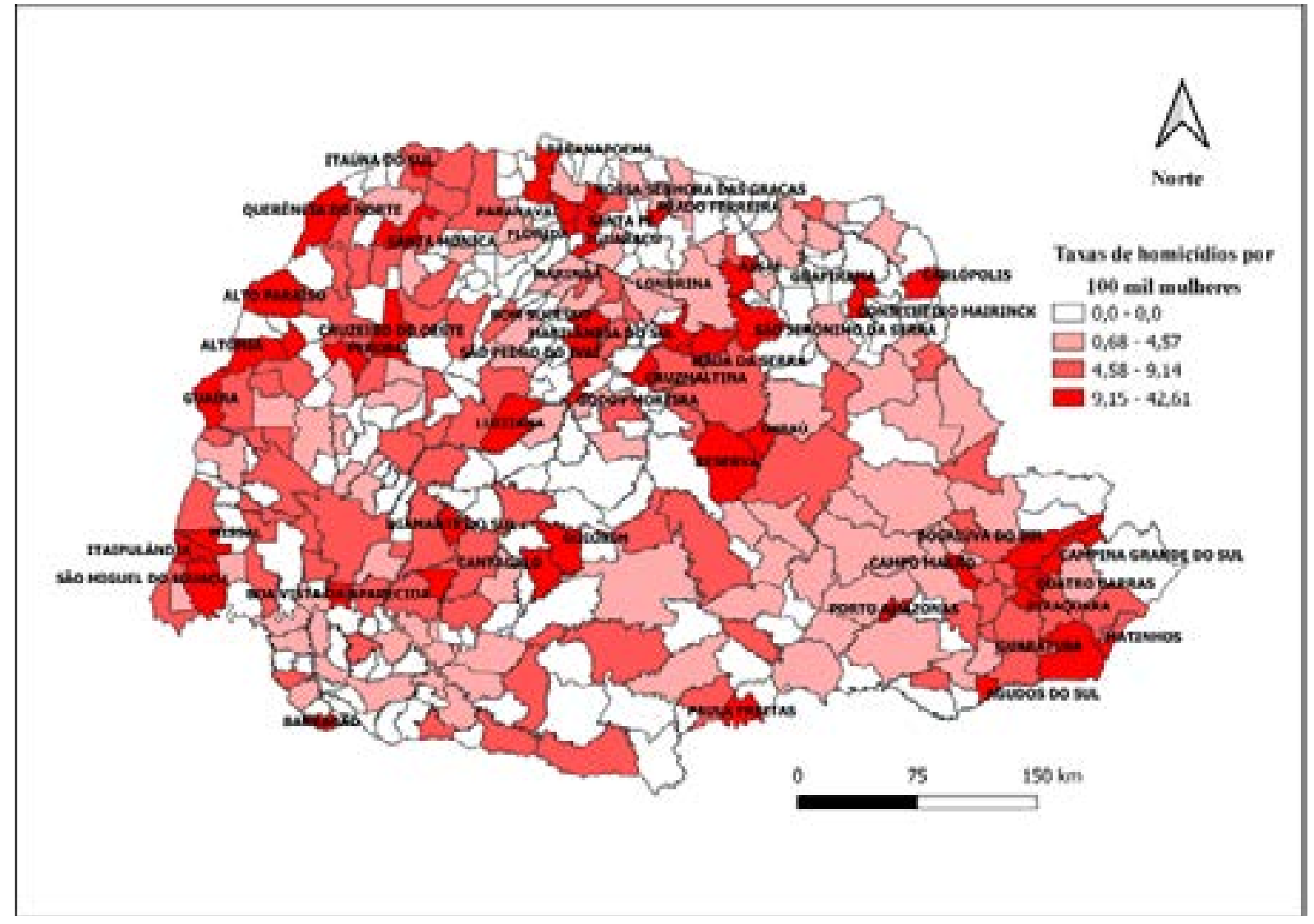

Fonte: SIM; IBGE, compilado pelos autores (2020).

Nota: Apenas foram nomeados os municípios que se enquadram na categoria com as taxas mais altas, juntamente com os municípios de Londrina, Maringá e Paranavaí, para visualização dos locais críticos.

Conforme pode ser observado na Figura 1, a análise espacial das taxas médias de homicídios por 100 mil mulheres no Paraná (2014 a 2018) revela que a distribuição desses 
homicídios é bastante heterogênea. Dentre os 399 municípios, há muitos que registraram nenhum homicídio de pessoas do sexo feminino no período, sendo representados pela cor branca e bastante espalhados pelo estado, sendo marcadamente municípios de menor população. Por outro lado, grande parte dos municípios se situam na faixa mais clara, que compreende valores que vão de 0,68 até a taxa média registrada no estado, que é de 4,57 homicídios por 100 mil mulheres. Esse grupo aparece mais notadamente nas regiões dos campos gerais, centro-sul e sudoeste do Paraná. E nas tonalidades mais escuras estão os municípios com as taxas superiores à média do estado, ou seja, acima de 4,57 homicídios por 100 mil mulheres. Embora esses municípios também estejam distribuídos de maneira bastante espalhada, parecem se sobressair mais na porção leste do estado, que compreende Curitiba e sua região metropolitana, junto com a região litorânea, assim como na porção oeste do estado, acompanhando a região das proximidades da fronteira com o Paraguai e o Mato Grosso do Sul. Também são observados alguns clusters com taxas superiores às médias do estado em municípios do entorno das regiões de Londrina (em direção ao Sul, incluindo São Jerônimo da Serra, Mauá da Serra, Cruzmaltina até Imbaú e Reserva), Paranavaí (em direção ao oeste, incluindo Santa Mônica e Itaúna do Sul) e Maringá (em direção ao norte, incluindo Iguaraçu, Santa Fé e Nossa Senhora das Graças até Paranapoema, já na divisa com o estado de São Paulo), assim como uma faixa que acompanha o entorno do traçado da BR277 no oeste do estado.

O Estudo aponta que os homicídios contra mulheres e meninas existem nas mais diversas regiões do estado do Paraná, porém, sua distribuição geográfica não se dá de forma homogênea. Os homicídios femininos persistem tanto na capital, grandes cidades e regiões metropolitanas, como no interior, inclusive em municípios de menor porte. Observa-se maior ocorrência de homicídios em áreas de maior vulnerabilidade social e de menor qualidade de vida urbana. Regiões de urbanização acelerada acompanhadas de desenvolvimento econômico insuficiente, desigual e desordenado parecem ser responsáveis por grande parte dos homicídios. A assimilação de características territoriais com maiores riscos de homicídios entre determinados grupos populacionais pode contribuir com a identificação de localidades e grupos mais vulneráveis e na criação de políticas públicas mais eficientes para o enfrentamento dessa problemática. Compreender e visibilizar esses acontecimentos e suas variações territoriais é um desafio permanente e uma forma eficiente de contribuir para a melhoria da saúde pública (WANZINACK; SIGNORELLI; REIS, 2018). 


\section{Considerações Finais}

Foi possível verificar através deste estudo que no período compreendido entre 2014 e 2018 houve uma redução na ordem de 27\% dos homicídios contra pessoas do sexo feminino no estado do Paraná. Por meio da análise dos dados oficiais do Ministério da Saúde, observou-se que os homicídios de mulheres e meninas no estado do Paraná, em grande parte, caracterizam-se por lesões decorrentes de disparo de arma de fogo (44\%), seguido por lesões por objetos perfurantes ou cortantes (32\%). As vítimas em sua maioria são mulheres brancas (77\%); de perfil adulto jovem, com idade variando entre 15 e 34 anos; o estado civil é composto por mulheres solteiras e de baixa escolaridade; e o local de ocorrência dessas agressões foi em sua maioria nos seus próprios domicílios.

Uma grande dificuldade e limitação na pesquisa sobre homicídios contra mulheres é a caracterização dos óbitos como feminicídios, evidenciando sua relação com a violência de gênero. Atualmente, os bancos de dados oficiais do Ministério da Saúde não dispõem de informações mais detalhadas nos sistemas de informação sobre mortalidade. No caso do SIM, não constam nos registros a relação entre o perpetrador e a vítima, nem os motivos da morte por agressão, o que impossibilita caracterizar quantos desses homicídios foram feminicídios. Conhecer os motivos do homicídio e realidades de cada vítima seria importante para planejar, custear e avaliar políticas públicas para minimização da violência contra as mulheres.

Outro fator que poderia ser uma limitação de nossos resultados é o critério autodenominação no quesito raça/cor, uma vez que a raça/cor da população no censo do IBGE é autodenominada pelo entrevistado(a), ou seja, a própria pessoa que declara sua raça/ cor. Já no caso da vítima de homicídio, a raça/cor é atribuída pelo médico (a) legista, o que poderia gerar erros na determinação em relação ao quesito raça/cor autodeclarado, uma vez que não parte da denominação da própria pessoa, mas sim de terceiros.

Territorialmente, observamos que a distribuição dos homicídios de mulheres e meninas no Paraná é bastante heterogênea, com regiões mais violentas no entorno de Curitiba e sua região metropolitana, no litoral, nas áreas de fronteira com o Paraguai e o Mato Grosso do Sul, e ainda no entorno de cidades de grande/médio porte do interior, como Londrina, Maringá e Paranavaí. Um outro ponto importante a ser ressaltado é que o fato de um município ter baixas taxas de homicídios não implica que nele não existem outras formas 
de violências, pois a violência pode se manifestar das mais diversas formas. Portanto, esta pesquisa direciona o olhar para apenas uma única forma de violência, que são os homicídios, mesmo cientes de que outras modalidades de violência acontecem concomitantemente e, muitas vezes, podem possuir relação com os homicídios.

A violência contra as mulheres é uma forma de desigualdade que precisa ser combatida. Seu enfrentamento consta como uma das diretrizes dos Objetivos do Desenvolvimento Sustentável (ODS), cujo $5^{\circ}$ objetivo preconiza a equidade de gênero e o empoderamento das mulheres e meninas. Os homicídios são o ápice da violência contra as mulheres e meninas, pois anulam completamente a vida, sendo, portanto, prioritária a sua prevenção na agenda de combate às violências, almejando o Desenvolvimento Sustentável.

\section{Referências}

ARAÚJO, E. M. D.; COSTA, M. D. C. N.; HOGAN, V. K.; MOTA, E. L. A. et al. Diferenciais de raça/cor da pele em anos potenciais de vida perdidos por causas externas. Rev. Saúde Pública, v. 43, n. 3, p. 405-412, 2009. Disponível em: https://www.redalyc.org/articulo.oa?id=67240177003.

BRASIL. Lei no 11.340, de 7 de agosto de 2006. Disponível em: http://www.planalto.gov.br/ccivil_03/_ato20042006/2006/lei/l11340.htm.

BRASIL. Lei no 13.104, de 9 de março de 2015. Altera o art. 121 do Decreto-Lei n².848, de 7 de dezembro de 1940, Código Penal, para prever o feminicídio como circunstância qualificadora do crime de homicídio, e o art. $1^{\circ}$ da Lei n 8.072, de 25 de julho de 1990, para incluir o feminicídio no rol dos crimes hediondos. Diário Oficial da União, 2015.

CARDOSO, M. P.; FAÚNDES, A. Mortalidade de mulheres em idade fértil devido a causas externas no município de Cascavel, Paraná, Brasil, 1991 a 2000. Cadernos de Saúde Pública, v. 22, p. 2241-2248, 2006.

CERQUEIRA, D.; LIMA, R.S.; BUENO, S., NEME, C.; FERREIRA, H.; COELHO, D. et al. Atlas da Violência 2018.

CERQUEIRA, D.; BUENO, S.; ALVES, P. P.; LIMA, R. S. D. et al. Atlas da Violência 2020.

DALTOÉ, C. M.; BAZZO, M. S. Primeiro ano de vigência da lei do feminicídio: casos concretos analisados pelo Ministério Público do estado do Paraná. 2018.

DAVID, L. M. V.; MINAMISAVA, R.; VITORINO, P. V. D. O.; ROCHA, M. J. P. et al. Profile of female deaths by homicide in the city of Goiânia. Revista Brasileira de Enfermagem, v. 73, 2020.

GARCIA, L. P.; FREITAS, L. R. S. D.; SILVA, G. D. M. D.; HÖFELMANN, D. A. Estimativas corrigidas de feminicídios no Brasil, 2009 a 2011. Panam. Salud Pública, v. 37, p. 251-257, 2015.

GOMES, I. S. Femicides: a long debate. Estudos Feministas, v. 26, n. 2, 2018.

KLEINSCHMITT, S. C.; WADI, Y. M.; STADUTO, J. A. Evolução espaço-temporal dos homicídios no estado do Paraná. Revista Brasileira de Estudos de Segurança Pública, v. 4, n. 1, 2010. 
LEITES, G. T.; MENEGHEL, S. N.; HIRAKATA, V. N. Female homicide in Rio Grande do Sul, Brazil. Revista Brasileira de Epidemiologia, v. 17, n. 3, p. 642-653, 2014.

LIMA, R. S.; BUENO, S. Anuário brasileiro de segurança pública 2019. Fórum Brasileiro de Segurança Pública. São Paulo, 13, 2019.

MENEGHEL, S. N.; HIRAKATA, V. N. Femicídios: homicídios femininos no Brasil. Revista de Saúde Pública, v. 45, p. 564-574, 2011.

NOGUEIRA, V. D.; XAVIER-GOMES, L. M.; BARBOSA, T. L. D. A. Mortalidade por homicídios em linha de fronteira no Paraná, Brasil. Ciência \& Saúde Coletiva, v. 25, p. 3107-3118, 2020.

ORGANIZAÇÃO MUNDIAL DA SAÚDE (OMS). Saúde sexual, direitos humanos e a lei. Tradução: Projeto T. R. P.; Interinstitucional entre Universidade Federal do Rio Grande do Sul et al. Porto Alegre: UFRGS, 2020.

REICHENHEIM, M. E.; DE SOUZA, E. R.; MORAES, C. L.; DE MELLO JORGE, M. H. P. et al. Violence and injuries in Brazil: the effect, progress made, and challenges ahead. The Lancet, v. 377, n. 9781, p. 1962-1975, 2011.

SOUZA, E. R. D.; MEIRA, K. C.; RIBEIRO, A. P.; SANTOS, J. D. et al. Homicídios de mulheres nas distintas regiões brasileiras nos últimos 35 anos: análise do efeito da idade-período e coorte de nascimento. Ciência \& Saúde Coletiva, v. 22, p. 2949-2962, 2017.

TAVARES, R.; CATALAN, V. D. B.; ROMANO, P. M. D. M.; MELO, E. M. Homicídios e vulnerabilidade social. Ciência \& Saúde Coletiva, v. 21, p. 923-934, 2016.

WAISELFISZ, J. J. Mapa da violência 2015: homicídio de mulheres no Brasil. Flacso Brasil, 2015.

WANZINACK, Clovis; SIGNORELLI, Marcos Claudio; REIS, Clóvis. Homicídios e determinantes socioambientais de saúde no Brasil: uma revisão sistemática da literatura. Cad. Saúde Pública, Rio de Janeiro, v. 34, n. 12, p. e00012818, 2018. Disponível em: www.scielo.br/scielo.php?script=sci_arttext\&pid=S0102-311X20180012020 $01 \& \operatorname{lng}=e n \& \mathrm{nrm}=$ iso.

WORLD HEALTH ORGANIZATION (WHO). Global status report on violence prevention 2014. 